\title{
Drug Expenditure Trends in the Canadian Provinces: Magnitude and Causes from 1998 to 2004
}

\section{Tendances en matière de dépenses en médicaments dans les provinces canadiennes : l'ampleur et les causes, de 1998 à 2004}

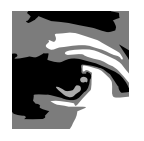

by STEVE MORGAN, PHD

Assistant Professor, Centre for Health Services and Policy Research

University of British Columbia

Vancouver, BC

Professeur adjoint, Centre de recherche sur les services de santé et les politiques

Université de la Colombie-Britannique

Vancouver, C.-B. 


\begin{abstract}
This analysis uses a consistent pan-Canadian dataset - Canadian CompuScript from IMS Health, Canada - to quantify trends in per capita drug expenditures within each Canadian province over the period of 1998 to 2004. The impacts of changes in six potential determinants of drug expenditure are calculated for every province. Each of the six detailed cost drivers falls into one of three broad categories: volume effects, price effects and therapeutic choices. Despite wide variation in expenditure levels, the rate and causes of provincial expenditure trends over time were roughly comparable. From 1998 to 2004, per capita expenditures on oral solid prescription drugs grew at a rate of over $10 \%$ per year in most provinces - several times faster than economic growth over the same period. This rapid expenditure growth has largely been due to increased utilization of medicines and a trend towards prescribing higher-cost drugs over time. Price changes had little impact on drug spending in all provinces.
\end{abstract}

\title{
Résumé
}

Cette analyse, servant à évaluer quantitativement les tendances dans les dépenses en médicaments par personne pour chaque province canadienne durant la période de 1998 à 2004, a été effectuée à l'aide d'une base de données pancanadienne cohérente, soit CompuScript Canada de IMS Health. On a calculé séparément pour chaque province l'incidence des changements affectant six causes potentielles de dépenses en médicaments. Ces six facteurs de coûts détaillés se divisent en trois grandes catégories : les effets du volume, les effets du prix et les choix thérapeutiques. En dépit de la grande différence entre les sommes consacrées aux médicaments d'une province à l'autre, le rythme et les causes des tendances provinciales en matière de dépenses par rapport au temps étaient à peu près comparables. De 1998 à 2004, les dépenses par personne pour les ordonnances de comprimés oraux ont connu une croissance de plus de $10 \%$ par an dans la plupart des provinces, ce qui est beaucoup plus élevé que la croissance économique durant la même période. Cette croissance rapide est largement due à l'accroissement de l'usage des médicaments et à la tendance à long terme vers la prescription de médicaments coûteux. L'augmentation des prix a une incidence minime sur les dépenses en médicaments dans toutes les provinces. 
$\mathrm{P}$ RESCRIPTION DRUGS ARE USED TO TREAT AN INCREASING RANGE OF HEALTH problems and have become a major component of the Canadian healthcare system. Indeed, costing over $\$ 18$ billion per year, they are second only to hospitals in terms of healthcare spending. They are also the fastest-growing component of healthcare expenditures, having increased by more than $10 \%$ per year for the past decade (Canadian Institute for Health Information [CIHI] 2005). Prudent management of drug expenditures is critical for the sustainability not only of pharmacare programs, but also of the healthcare system as a whole. For example, if policy could hold prescription drug expenditure constant for just one year, the savings (compared to current trends) could pay for 6,000 new doctors or 18,000 new nurses. What is perhaps most surprising about Canadians' expenditure on prescription drugs is not the size of this investment in healthcare, but lack of data concerning the nature of the investment: who is using prescription drugs; what medicines do they receive; and what outcomes result? Answers to these questions are essential to healthcare policy formulation and budget planning.

In this paper, I quantify the magnitude and causes of trends in prescription drug expenditure for each Canadian province and for each of three leading therapeutic categories. The purpose is to highlight utilization and pricing dynamics that may be worthy of investigation, and to illustrate the potential value of investing in even more detailed information about drug utilization and expenditure patterns (and the factors influencing them). Recent reports have examined the determinants of spending under provincial drug plans (Morgan 2002; Patented Medicine Prices Review Board [PMPRB] 2002), national expenditure trends (Morgan 2004a) and variations in the level of spending across provinces (Morgan 2004b). No report, however, has quantified comparable, market-level cost dynamics within Canadian provinces. The analysis presented here is based on the best available data for interprovincial analysis of population-level drug utilization and expenditure patterns - Canadian CompuScript from IMS Health, Canada. These data are used to quantify the relative and absolute impacts of various drug utilization and pricing patterns that influence per capita drug expenditures within each province over the period of 1998 to 2004.

\section{Data}

In recognition of the important role that prescription drug utilization plays in our healthcare system, a growing number of provinces are developing drug information systems that track the use of medicines by all residents. Ideally, these data systems will be used in conjunction with other data on individuals' health and healthcare use, such that the return on investment from pharmaceuticals can be suitably monitored. Just as financial analysts monitor returns on stock market investments, researchers and policy makers could study the variety of fundamentally important issues in this 
sector - drug access, use, safety, costs and benefits. Such information would assist in the design of policies to ensure that the right drugs are getting to the right patients.

Despite their great potential, provincial/territorial data systems are in their infancy. Only a few provinces (British Columbia, Saskatchewan and Manitoba) currently have systems that capture population-based drug utilization information, in contrast to datasets that track only those members of particular drug plans. While many more provinces have plans for population-based systems in the meantime, policy and practice can currently be informed, in part, by analysis of market-level expenditure trends and consumption patterns using data such as those collected by the Canadian Institute for Health Information (CIHI 2005) or those collected by private market-research companies. This study utilizes one such dataset - the Canadian CompuScript data from IMS Health, Canada - to depict a variety of drug use and expenditure dynamics for each province. The advantage of using an equivalent dataset across provinces is that it provides an opportunity to compare expenditure levels and trends across jurisdictions and to benchmark regional findings against the national average (until such time as "best practices" can be identified for benchmarking purposes).

The Canadian CompuScript Audit is based on data collected from over 2,100 retail pharmacies (approximately $30 \%$ of the Canadian market), stratified by province. IMS Health projects these sample data to the entire population in each province, except Prince Edward Island and Newfoundland and Labrador (data for which are combined owing to small population sizes). IMS Health, Canada provided quarterly data on prescription- and dollar- and unit-volume of prescription drugs from 1998 to 2004. To ensure accurate measures of the quantity of drugs consumed over time, the analysis is restricted to oral solid prescription drugs only: quantity measures for liquids, injectables, inhalables or creams can vary in ways that counts of solids, such as capsules and tablets, do not. The oral solids included in this study accounted for approximately $80 \%$ of each provincial market over the study period.

To measure details of how drug utilization and pricing patterns differ across and within therapeutic categories, drug datasets must be accompanied by or linked with therapeutic classification codes. The data used in this study identify 5,287 brand and generic versions of 1,508 types of oral solid drugs identified by active ingredient and dosage. IMS Health groups all these drugs by primary indication into 185 mutually exclusive drug classes. The leading five drug classes - accounting for $37 \%$ of expenditure on oral solid prescriptions in 2004 - were statins, proton pump inhibitors, serotonin reuptake inhibitors, angiotensin-converting enzyme (ACE) inhibitors and calcium channel blockers. Drug classes are further aggregated into 40 broad treatment categories. The five largest categories of treatment $-60 \%$ of 2004 expenditure - were cardiovascular drugs, psychotherapeutics, antispasmodic drugs (GI drugs), cholesterol agents and systemic anti-infectives.

The cost information in the IMS data includes professional fees and retail mark- 
ups. As there were no accurate means to remove the impact of professional fees on total expenditure, it must be noted that trends in prices reported here are affected in part by trends in length of prescriptions. The unit cost of a drug will be lower when prescriptions are "longer" because, holding constant the price charged for the drug itself, the professional fee paid per unit of the drug is lower if the prescription is for a larger numbers of units (e.g., a $\$ 9.00$ dispensing fee raises the cost per tablet by $\$ 0.30$ if the prescription is for 30 pills, and by only $\$ 0.09$ if the prescription is for 100 pills).

\section{Methods: Measuring Potential Determinants of Drug Expenditure Trends}

In order to describe expenditure trends, economists often divide total changes in expenditure into a price component and a quantity component (Berndt et al. 2000). The price component is typically calculated using a standard price index that tracks what it would cost to buy an unchanging basket of goods over time (e.g., the cost of a dozen eggs, a kilogram of bacon and three litres of beer). In the pharmaceutical context,

... health services researchers are adding more detail to drug spending analysis by recognizing that pharmaceuticals need not be viewed as a single monolithic market, but a spectrum of sub-markets for example, one might track what it would cost over time to purchase the "basket" of the drugs bought in a given year (say, 1998). Over time, actual expenditure may rise or fall compared to the cost of buying the original basket of goods.

The difference between the hypothetical cost of buying the original basket of goods and the actual amount spent in a given period (say, in 2004) is attributed to change in quantity of goods purchased.

The problem with the simple price-versus-quantity description of drug-spending trends is that it attributes all changes in the rate, type and intensity of pharmacotherapy used by a population to changes in quantity. Fortunately, however, health services researchers are adding more detail to drug spending analysis by recognizing that pharmaceuticals need not be viewed as a single monolithic market, but a spectrum of sub-markets denoted by therapeutic category and even chemical or drug class (Anderson et al. 1993; Dubois et al. 2000; Express Scripts 2002; Mehl 1984; PMPRB 2002; Steinberg et al. 2000). By measuring prices and quantities of drugs used at different levels of therapeutic categorization, analysts can quantify the many dynamics that might be hidden within a simple price-versus-quantity analysis. For example, in 
FIGURE 1. Determinants of per capita expenditure trends

\section{Total (or Annual) Change In Expenditure Per Capita}

Volume of Prescriptions

Change in number of prescriptions filled

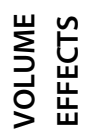

from 40 broad therapeutic categories

Prescription Size

Change in average number of

units per prescription filled

\section{Therapeutic Mix}

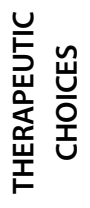

Change in average mix of drug classes selected

from within therapeutic categories

$+$

Drug Mix

Change in average mix of drug types

selected from within drug classes

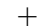

\section{Price Changes}

Change in prices paid per unit of

岂

brand and generic versions of drugs

$+$

Generic Use

Change in average price paid per unit

of drugs due to use of generics

addition to tracking the price of brand and generic versions of a given drug, one can also track changes in the average price of the brand and generic purchases combined. The differences between such measures would illustrate the impact of increased or reduced generic drug use over time (Morgan 2002, 2004a). Such dynamics are ignored by conventional economic analyses of drug-expenditure trends.

The conceptual framework used in this paper takes advantage of the therapeutic classifications in the IMS Health data to illustrate six different types of utilization and price dynamics in the Canadian pharmaceutical sector. This conceptual model for decomposing drug expenditure trends is illustrated in Figure 1. For ease of interpretation, this figure depicts the model in an additive fashion. Mathematically, this frame- 
work is actually quantified by calculating Fisher's ideal price and quantity indexes at different levels of the therapeutic classification system. These indexes interact multiplicatively to explain exact total changes in expenditure (Morgan 2004a). Results presented below, however, have been converted to percentage terms, using logarithmic decompositions to preserve the expenditure equality in an additive form: that is, all percentage results reported below add up (in a conventional $1+1=2$ sense) to explain the exact observed expenditure trends.

The six potential determinants of expenditure quantified in this study fall into three broad categories of cost drivers: volume effects, therapeutic choices and price effects. Volume effects are factors that relate to the absolute volume of prescription drug therapy received by a population. This includes the per capita volume of prescriptions received from broad categories of treatment and the average size of prescriptions that are filled. Average prescription size may compound or counteract the cost impact of changes in the number of prescriptions dispensed; trends may, for example, reflect the use of fewer but longer prescriptions over time. Changes in the volume of therapy used by a population are not necessarily a cause for concern, because policy should generally encourage access to medicines where appropriate. Analysis of utilization trends or regional variations may, however, indicate areas deserving of detailed investigation if there is potential for inappropriate or cost-ineffective use.

Therapeutic choices are factors that influence the cost of therapy through changes in the selection of the type or form of drug selected per course of treatment. Therapeutic choices include changes in the mix of drug classes from which drugs are prescribed and changes in the types of drugs selected within drug classes. The broader changes are referred to as "therapeutic mix" and reflect the cost impact of changes in market shares accruing to specific classes of drug within therapeutic categories. This includes such dynamics as the increased use of angiotensin II receptor antagonists within the therapeutic category of cardiovascular drugs. The narrower "drug mix" cost dynamic reflects changes in the selection of specific drug types within a drug class: e.g., changes from simvastatin to atorvastatin within the class of statin drugs (used to treat high cholesterol). Such cost drivers are less likely to have major effects on health outcomes than broader therapeutic choices; thus, finding that significant expenditure stems from changing drug mix may provoke prudent policy intervention to steer utilization towards cost-effective choices (Garber 2001). In contrast, finding that significant expenditure stems from changes in the broader therapeutic mix may provoke policies that focus on educating prescribers and patients about cost-effective treatment choices for a given condition, such as initiating treatment for hypertension with effective and low-cost diuretics (Therapeutics Initiative 2003).

Finally, price effects are factors that influence the cost of therapy received by a population without altering the quantity or type of drug used. Price factors include the change in price of products already on the market and changes in the rate at which 
generic drugs are selected, when available. Such factors have no significant impact on the quality of health outcomes obtained per course of such therapy. As such, they are common targets for policy intervention, whether that involves price negotiations or generic substitution policies.

\section{Findings}

Table 1 lists the 1998 and 2004 levels of per capita expenditure on oral solid prescription drugs for Canada as a whole and for each province. The average annual growth in these per capita expenditures between 1998 and 2004 is broken down into the annual impact of each potential cost driver. These percentages report how much per capita drug spending would have changed in the given province if only the cost driver in question had altered over time while all other cost drivers were held at their 1998 levels. The sum of all six individual cost drivers will equal the total percentage change in spending for the given province. Subtotals are also provided for the groupings of volume effects, therapeutic choices and price effects.

In addition to previously documented variation in levels of expenditure (Morgan 2004b), rates of expenditure growth also varied across provinces between 1998 and 2004. Rates of growth were most rapid in Manitoba, Quebec and Alberta, and least rapid in Nova Scotia, Prince Edward Island/Newfoundland and Labrador (combined) and Saskatchewan. The rapid growth in per capita expenditures observed in Manitoba - where expenditure per capita almost tripled from $\$ 154$ (well below the national average) to $\$ 435$ (just above the national average) - may have been influenced in part by Internet pharmacy sales to the United States, some of which may be captured by the IMS data. The rapid growth in expenditure observed in Quebec is noteworthy because expenditure per capita in that province was among the highest in Canada in both 1998 and 2004.

Despite variations in expenditure levels and rates of growth, the relative sources of expenditure escalation over time were similar across provinces. Volume effects accounted for a majority of the increase in per capita expenditure on oral solid prescription drugs in every province. Most of these volume effects were due to the number of prescriptions purchased from across the 40 broad therapeutic categories. Increased prescription sizes added to total volume in all provinces except Quebec, where average length of prescriptions fell slightly. The impact of longer prescriptions was highest in Atlantic Canada, Saskatchewan and Alberta. Changes in the average size of prescription for a small number of high-volume drugs - including tamsulosin, donepezil, clopidogrel and alendronate - generated a significant cost impact in Alberta and Atlantic Canada; significant growth in the length of many classes of prescription was observed during 2002 in Saskatchewan.

Changes in therapeutic choices between 1998 and 2004 were sufficient to increase 
Drug Expenditure Trends in the Canadian Provinces: Magnitude and Causes from 1998 to 2004

TABLE 1. Magnitude and determinants of change in per capita expenditure on oral solid prescription drugs among Canadian provinces, 1998 to $2004^{*}$

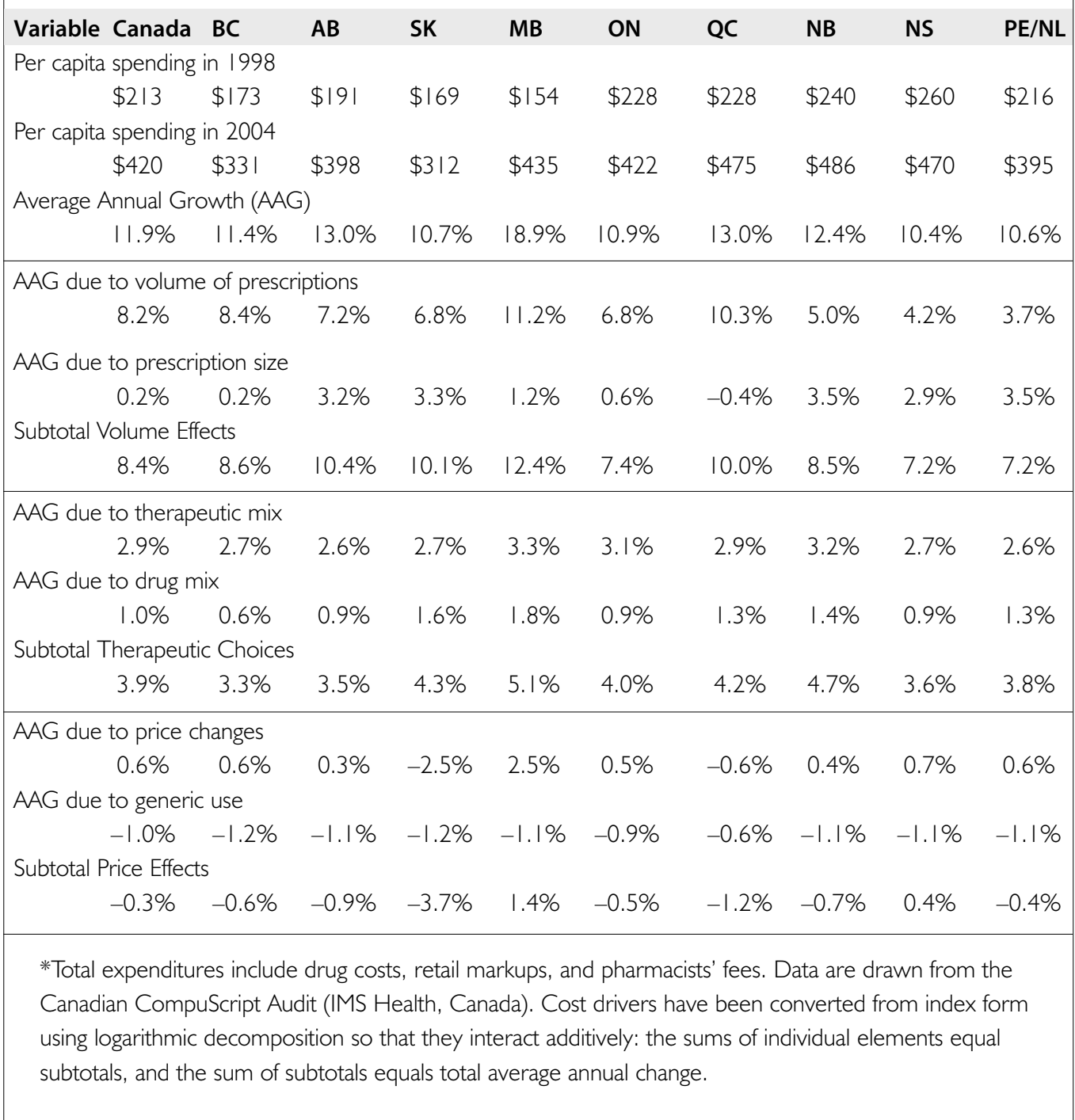

per capita expenditures by $3.3 \%$ to $5.1 \%$ per year, depending on the province. The cost impact of therapeutic choices was lowest in British Columbia, Alberta and Nova Scotia. In all provinces, decisions concerning the selection of classes of drug from which to prescribe (therapeutic mix) had a larger cost impact than the selection of drug types within classes (drug mix). This is because there are greater cost differences between treatment alternatives across drug classes (e.g., between thiazide diuretics 
and ACE inhibitors for the treatment of hypertension) than there are between treatment alternatives within drug classes (e.g., between the ACE inhibitors enalapril or ramipril).

In contrast to volume effects and therapeutic choices, price effects had a modest impact on per capita expenditures at a provincial level. In most provinces, price inflation in and of itself increased per capita drug expenditures by less than $1 \%$ per year between 1998 and 2004. Furthermore, savings generated from the increased use of generic drugs outweighed the cost impact of observed price increases in most provinces. Manitoba was one exception to these rules. Average unit prices in Manitoba increased by an average rate of $2.5 \%$ per year between 1998 and 2004, largely owing to a 7\% rise in unit prices during the second quarter of 1999 (data not shown). Again, the effects of Internet pharmacy sales to the United States may, in part, be responsible for anomalous findings for Manitoba. Other provinces with unusual price trends include Quebec and Saskatchewan, where prices actually fell over the period of analysis. The significant decline in prices in Saskatchewan appears to have been due to a $23 \%$ increase in average prescription size during the first quarter of 2002, which reduced average unit prices (including dispensing fees) by nearly $18 \%$ in the same quarter (data not shown). Similarly, during the third quarter of 2001 in Quebec, unit prices declined by $5 \%$ and prescription size increased by $5 \%$; both measures remained otherwise relatively stable for Quebec over the period.

\section{Leading Therapeutic Categories}

Table 2 lists the 1998 and 2004 magnitude and broad sources of change in per capita expenditure in the leading three categories of oral solid prescription drugs for Canada and for each province: cardiovasculars, psychotherapeutics and antispasmodics. The cardiovascular category is dominated by medicines primarily indicated for treating hypertension. Trends in this category between 1998 and 2004 exhibit the impact of rapid growth in the use of ACE inhibitors - a trend started earlier in the 1990s (Wolf et al. 1999). By 1998, ACE inhibitors accounted for approximately one-third of prescriptions in this category. Annual purchase of ACE inhibitors and related angiotensin II receptor blockers (ARBs) grew by over 18 million prescriptions across Canada, to account for approximately half of the total volume of cardiovascular prescriptions written in 2004. This appears as a volume effect and as a therapeutic choice, the latter because the cost per prescription for ACE inhibitors and ARBs can be many times greater than that of beta-blockers or thiazide diuretics, which are also indicated for treating hypertension.

The expenditure trends in the category of psychotherapeutic agents reflect a pattern of expanded use and broad changes in the average type of drug prescribed in this segment. Because this therapeutic category of drugs contains tranquilizers, medicines 
Drug Expenditure Trends in the Canadian Provinces: Magnitude and Causes from 1998 to 2004

TABLE 2. Magnitude and determinants of change in per capita expenditure on
oral solid prescription drugs among Canadian provinces, 1998 to $2004^{*}$

Cardiovascular Drugs

Canada BC

$\begin{array}{lllllll}A B & \text { SK } & \text { MB } & \text { ON } & \text { QC } & \text { NB } & \text { NS }\end{array}$

PE/NL

Per capita spending in 1998

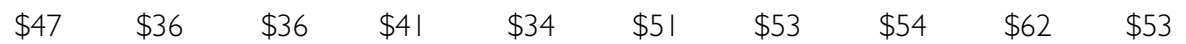

Per capita spending in 2004

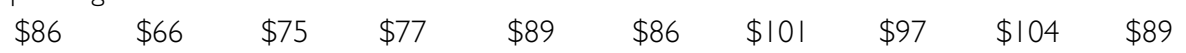

Average Annual Growth (AAG)

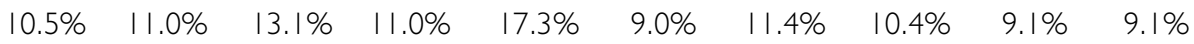

Volume Effects

$\begin{array}{llllllllll}9.0 \% & 9.6 \% & 12.1 \% & 9.1 \% & 11.8 \% & 7.5 \% & 10.0 \% & 9.0 \% & 7.6 \% & 7.7 \%\end{array}$

Therapeutic Choices

$\begin{array}{llllllllll}1.3 \% & 1.7 \% & 1.0 \% & 1.9 \% & 2.6 \% & 1.3 \% & 1.6 \% & 1.4 \% & 0.9 \% & 1.4 \%\end{array}$

Price Effects

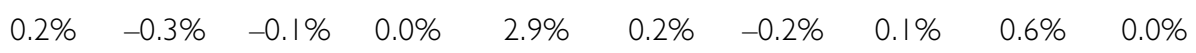

Psychotherapeutic Drugs

$\begin{array}{llllllllll}C A & B C & A B & \text { SK } & \text { MB } & \text { ON } & \text { QC } & \text { NB } & \text { NS } & \text { PE/NL }\end{array}$

Per capita spending in 1998

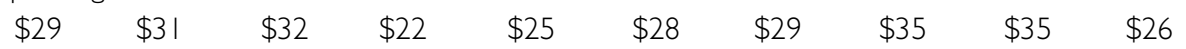

Per capita spending in 2004

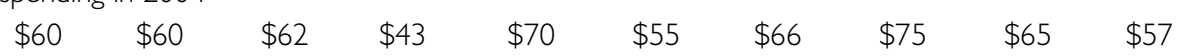

Average Annual Growth (AAG)

$\begin{array}{llllllllll}12.8 \% & 11.7 \% & 11.5 \% & 12.0 \% & 18.7 \% & 11.7 \% & 14.9 \% & 13.9 \% & 10.9 \% & 13.8 \%\end{array}$

Volume Effects

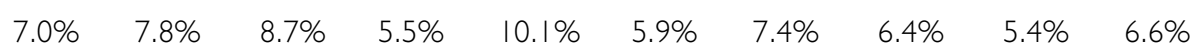

Therapeutic Choices

Price Effects

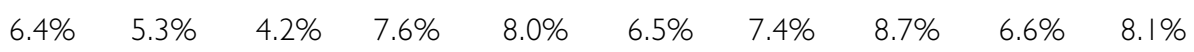

$-0.6 \% \quad-1.4 \% \quad-1.4 \% \quad-1.1 \% \quad 0.6 \% \quad-0.7 \% \quad 0.1 \% \quad-1.2 \% \quad 1.1 \% \quad-0.9 \%$

Antispasmodic (GI) Drugs

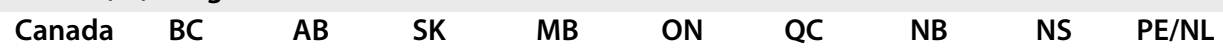

Per capita spending in 1998

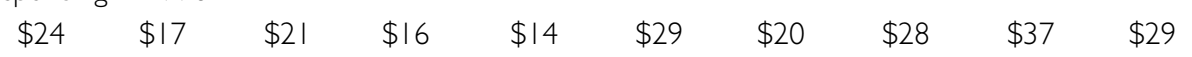

Per capita spending in 2004

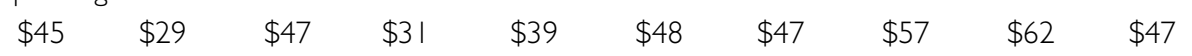

Average Annual Growth (AAG)

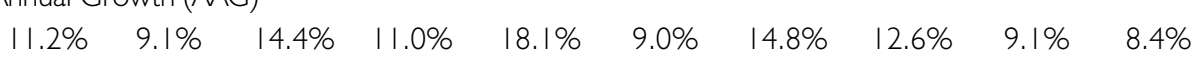

Volume Effects

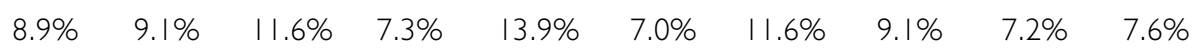

Therapeutic Choices

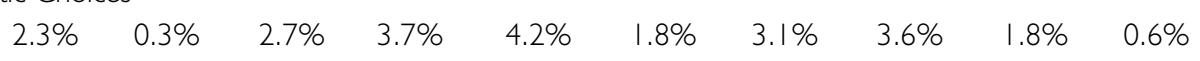

Price Effects

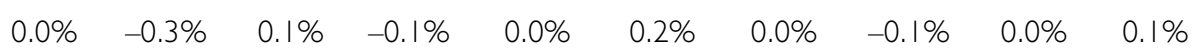

* See note on Table I 
to treat depression and medicines to manage psychoses, the therapeutic choices herein must be interpreted with caution. While the annual costs were driven substantially by the broadly defined therapeutic mix, this trend is primarily due to increased use of certain atypical anti-psychotics. This phenomenon is clinically important and has significant financial implications; it should not, however, be confused with changes in the drug mix within, say, the category of selective serotonin reuptake inhibitors (SSRIs, commonly used to treat depression). The more narrow drug mix patterns within the class of SSRIs were a modest contributor to drug expenditures in all provinces; however, increased use of SSRIs is the major cause of volume effects in the psychotherapeutic category.

Within the category of antispasmodic drugs, expenditure trends were dominated by market dynamics for drugs indicated for the treatment of ulcers, heartburn and gastroesophageal reflux disease. In 1998, nearly half the prescriptions written for this the broadly therapeutic category were for histamine-2 receptor antagonists (H2RAs), which are ulcer drugs first marketed in the late 1970s. However, by 2004, over half the prescriptions written for this therapeutic category were for proton pump inhibitors (PPIs). As with ACE inhibitors among cardiovascular drugs, rapid increase in the use of PPIs is reflected as volume effects and therapeutic choices for the category of antispasmodic drugs. This is because the cost of brand-name PPIs is much higher than the cost of generic H2RAs. A generic PPI became available in 2004, and it is expected that savings in this category should increase as more PPI products become available in lower-cost generic form.

\section{Discussion}

From 1998 to 2004, per capita expenditures on oral solid prescription drugs grew at a rate of over $10 \%$ per year in every province - several times faster than economic growth over the same period. Increases in the volume of prescription drugs purchased explained approximately two-thirds of the increase in per capita expenditure observed in all provinces. Without evidence concerning the appropriateness of prescribing, it is difficult to assess whether trends towards increased utilization will result in commensurate increases in health benefits. An educated guess may be that both over- and underuse of pharmaceuticals is occurring in Canadian provinces. However, educated guesses should not be used to formulate policy - particularly policies as important to the health of Canadians, and to the overall cost of the Canadian healthcare system, as investment in pharmaceutical care. It is therefore critical to develop systems to monitor drug utilization to be sure that the right patients are getting the right drugs. If policies and practices ensure such appropriate use, health gains will be achieved through increased use of prescribed medicines.

The cost of health gains achieved through the use of medicines (even those pre- 
scribed appropriately) is determined largely by therapeutic choices. These decisions were second only to increased drug use in terms of their impact on per capita drug expenditures in all provinces. Moreover, in leading therapeutic categories, increased use of medicines was also influenced by changes in the types of products most heavily promoted for given conditions; thus, even the volume effects measured in this study may be influenced by the intensity with which newer, patented drug products are promoted. Notwithstanding that possibility, the cost impact of "pure" therapeutic choices changes in the type of product selected from within broad therapeutic categories - was sufficient to increase per capita spending by about $3 \%$ per year in all provinces. Changes in the selection of specific drugs within drug classes added to this increase. The financial implications of these dynamics are significant: the combined effects of therapeutic choices for Ontario alone were sufficient to increase annual drug spending in that province by $\$ 700$ million in 2004 .

\section{Drug policy can have an effect on market dynamics and, therefore, drug costs and health outcomes.}

Drug policy can have an effect on market dynamics and, therefore, drug costs and health outcomes. The cost impacts of volume effects, and especially of therapeutic choices, were relatively low in British Columbia over the period studied. This finding may be due to the $\mathrm{BC}$ government's outcomes-based approach to covering comparable drugs and drug products (Morgan et al. 2004).

Over the period of analysis, public subsidy for proton pump inhibitors, COX-2 inhibitors and atypical antipsychotics was restricted though a special authority process in British Columbia; this limited both the volume of prescriptions and the therapeuticmix cost impact of these blockbuster drug categories. Similarly, in 1995 and 1997, the $\mathrm{BC}$ Pharmacare program implemented a reference drug program to limit the cost impact of product mix within leading therapeutic classes. Because major private insurance carriers in the province have adopted them, provincial drug-utilization dynamics may have been altered significantly by BC Pharmacarés coverage policies.

Whether one is concerned about drug products or the policies that affect their utilization, determining the impacts on patient health is critical to the interpretation of spending trends. Because health outcomes are the "return on investment" in pharmaceutical care, greater efforts need to be made to track them. Canada's federal, provincial and territorial ministers of health have begun to establish a National Prescription Drug Utilization Information System (NPDUIS) to "provide critical analyses of price, utilization and expenditure trends so that Canada's health system has more comprehensive, accurate information on how prescription drugs are being used and sources of cost increases" (PMPRB 2004). For the full benefit of national 
standards and data systems to be realized, drug information systems must reach beyond public claims data to capture all prescription drug purchases of all Canadians. Moreover, drug utilization information must be linked to information about patient health and health services use so that decision-makers can formulate policy based on evidence of the full spectrum of patient outcomes and health system impacts that result from prescription-drug consumption. Doing so can help ensure that Canada's annual increase in prescription-drug expenditure generates as much health benefit as the 6,000 new doctors or 18,000 new nurses that could otherwise be purchased with the extra funds.

\section{ACKNOWLEDGMENTS}

IMS Health, Canada provided data for this research project. Steve Morgan is supported in part by a New Investigator Award from the Canadian Institutes of Health Research and a Scholar Award from the Michael Smith Foundation for Health Research. IMS Health, the Canadian Institutes of Health Research and the Michael Smith Foundation for Health Research did not direct, in any way, the study design, the analysis and interpretation of data, the writing of the report or the decision to submit the paper for publication. All opinions expressed herein are solely those of the author

Correspondence may be directed to: Steve Morgan, Centre for Health Services and Policy Research, University of British Columbia, 429 IRC Bldg, 2194 Health Sciences Mall, Vancouver. Tel: 604 822-7012; E-mail : morgan@chspr.ubc.ca

\section{REFERENCES}

Anderson, G.M., K.J. Kerluke, I.R. Pulcins, C. Hertzman and M.L. Barer. 1993.“Trends and Determinants of Prescription Drug Expenditures in the Elderly: Data from the British Columbia Pharmacare Program." Inquiry 30(2): 199-207.

Berndt, E.R., D.M. Cutler, R.G. Frank, Z. Griliches, J.P. Newhouse and J.E. Triplett. 2000. "Medical Care Prices and Output." In A.J. Culyer and J.P. Newhouse, eds., Handbook of Health Economics, vol. 1 (pp. 119-80). Amsterdam: Elsevier Science B.V.

Canadian Institute for Health Information (CIHI). 2005. Drug Expenditures in Canada 19852004. Ottawa: Author.

Dubois, R.W., A.J. Chawla, C.A. Neslusan, M.W. Smith and S. Wade. 2000.“Explaining Drug Spending Trends: Does Perception Match Reality?" Health Affairs (Millwood) 19(2): 231-39. Express Scripts. 2002. 2001 Drug Trend Report. Maryland Heights, MO: Express Scripts. Garber, A.M. 2001. "Evidence-Based Coverage Policy." Health Affairs (Millwood) 20(5): 62-82. Mehl, B. 1984. "Indicators to Control Drug Costs in Hospitals." American Journal of Hospital Pharmacy 41(4): 667-75.

Morgan, S.G. 2002."Quantifying Components of Drug Expenditure Inflation: The British Columbia Seniors' Drug Benefit Plan." Health Services Research 37(5): 1243-66. 
Morgan, S.G. 2004a. "Drug Spending in Canada: Recent Trends and Causes." Medical Care 42(7): 635-42.

Morgan, S.G. 2004b. "Sources of Variation in Provincial Drug Spending." Canadian Medical Association Journal 170(3): 329-30.

Morgan, S., K. Bassett, K. and B. Mintzes. 2004. "Outcomes-Based Drug Coverage in British Columbia." Health Affairs (Millwood) 23(3): 269-76.

Patented Medicine Prices Review Board. 2002. Provincial Drug Plans Overview Report: Pharmaceutical Trends 1995/96-1999/00. Ottawa: Author.

Patented Medicine Prices Review Board. 2004 (July 28). National Prescription Drug Utilization Information System (NPDUIS). Retrieved July 30, 2005. < http://www. pmprb-cepmb.gc.ca/english/view. asp? $\mathrm{x}=1168 \mathrm{mp}=68>$.

Steinberg, E.P., B. Gutierrez, A. Momani, J.A. Boscarino, P. Neuman and P. Deverka. 2000. "Beyond Survey Data: A Claims-Based Analysis of Drug Use and Spending by the Elderly." Health Affairs (Millwood) 19(2): 198-211.

Therapeutics Initiative. 2003.

Therapeutics Letter 47: The Answer: Thiazides First-Line for Hypertension. Retrieved July 30, 2005. < http://www. ti.ubc.ca/pages/letter39.htm $>$.

Wolf, H.K., P. Andreou, I.R. Bata, D.G. Comeau, R.D. Gregor, G. Kephart et al. 1999."Trends in the Prevalence and Treatment of Hypertension in Halifax County from 1985 to 1995." Canadian Medical Association Journal 161(6): 699-704.
Centre for

Health Services and Policy Research

UBC's Centre for Health Services and Policy Research is proud to present its I8th annual health policy conference:

\section{Toward a National Pharmaceuticals Strategy \\ Lessons from Abroad}

\author{
February 9 and 10, 2006 \\ Vancouver, Canada
}

Join leading experts and policy makers from Australia, New Zealand, the United Kingdom, the United States and

Canada as they explore international perspectives on issues and best practices in pharmaceuticals policy.

Speakers - including Sir Michael Rawlins, Lloyd Sansom, Wayne McNee and Robert Evans - will discuss evidence and values in drug coverage decisions, drug safety and postmarketing surveillance, national formularies and price control, and challenges to pharmaceutical policy reform.

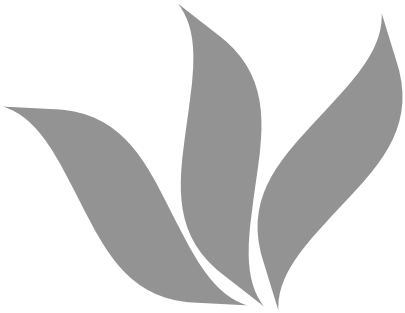

www.chspr.ubc.ca/hpc

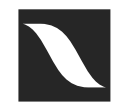

